\title{
P I 8- I 4 LB. Vacc-4x HIV p24-like peptide vaccine-associated increase of CD4 T-cells in chronically infected HIV-I patients on antiretroviral therapy
} P Bengtsson*1, I Baksaas ${ }^{1}$, M Sommerfelt ${ }^{1}$, B Sörensen ${ }^{1}$ and D Kvale ${ }^{2}$

Address: ${ }^{1}$ Bionor Immuno AS, Oslo, Norway and ${ }^{2}$ Oslo University Hospital, Oslo, Norway

* Corresponding author

from AIDS Vaccine 2009

Paris, France. 19-22 October 2009

Published: 22 October 2009

Retrovirology 2009, 6(Suppl 3):P4|3 doi:I0.I I86/I742-4690-6-S3-P4I3

This abstract is available from: http://www.retrovirology.com/content/6/S3/P4I3

(C) 2009 Bengtsson et al; licensee BioMed Central Ltd.

\section{Background}

Since its implementation more than a decade ago combination Antiretroviral Therapy (ART) has had a dramatic effect on HIV-1 induced mortality and morbidity. However, $15-20 \%$ of the patients initiating ART do not regain CD4 T-cells despite an effective suppression of HIV1mRNA levels in blood. The incomplete therapeutic effect leaves these patients at elevated risk of disease complications and death. Attempts to reduce clinical events through IL-2 induced stimulation of CD4 T-cells in the ESPRIT and SILCAAT studies have not proven to be successful. Until further research has given better opportunities for a successful direct induction of functional CD4 cells a logical alternative may be to increase CD4 counts indirectly by improving anti-HIV effect while on ART using antigen-specific immune stimulation with an effective HIV-vaccine.

\section{Methods}

In a Phase II trial with Vacc-4x, a synthetic and specific peptide vaccine to HIV-1 p24Gag, the increase of CD4 cells was studied in 37 chronically infected HIV patients on ART and with varying baseline CD4 T-cell counts. The median duration of ART prior to Vacc- $4 \mathrm{x}$ immunization was 4.5 years and preART CD4 counts were median 295 cells/uL.

\section{Results}

The average increase of CD4 counts was $9 \%(P<0,05)$ above baseline at 585 cell/uL (mean) 6 weeks after immu- nization. For patients with baseline CD4 level $<500$ cells/ $\mathrm{uL}(\mathrm{n}=11)$ the increase was $25 \%(\mathrm{P}<0,05)$ or 105 cells/ $\mathrm{uL}$. Only a few patients had a baseline CD4 count $<400$ (n $=3$ ) with an average increase of $32 \%$ (NS).

\section{Conclusion}

Patients on ART immunized with Vacc-4x experienced increased CD4 counts. The effect appeared more pronounced in patients with lower baseline CD4 counts $(<400-500)$. In a previous study (ACTG 384) CD4 increase for patients (preART CD4<300) was minimal after 120 weeks on ART (RobbinsCID 2009,48, 350-61). 